\title{
Um antropólogo na Mata ou Valores e ideais da formação universitária após a expansão
}

An anthropologist in the Brazilian Zona da Mata or Values, ideals, and diversity in higher education

\section{Guillermo Vega Sanabria}

\section{(2) OpenEdition}

Edição electrónica

URL: http://journals.openedition.org/aa/7662

DOI: 10.4000/aa.7662

ISSN: 2357-738X

\section{Editora}

Programa de Pós-Graduação em Antropologia Social (UnB)

Edição impressa

Paginação: 58-77

ISSN: 0102-4302

\section{Refêrencia eletrónica}

Guillermo Vega Sanabria, «Um antropólogo na Mata ou Valores e ideais da formação universitária após a expansão», Anuário Antropológico [Online], v.46 n. 1 | 2021, posto online no dia 03 janeiro 2021, consultado o 28 abril 2021. URL: http://journals.openedition.org/aa/7662 ; DOI: https://doi.org/ 10.4000/aa.7662

\section{(c) $($ ) $\odot \odot$}

Anuário Antropológico is licensed under a Creative Commons Atribuição-Uso Não-Comercial-Proibição de realização de Obras Derivadas 4.0 International. 


\title{
Um antropólogo na Mata ou Valores e ideais da formação universitária após a expansão
}

\author{
An anthropologist in the Brazilian Zona da Mata or Values, ideals, and diversity in \\ higher education
}

DOI: https://doi.org/10.4000/aa.7662

Guillermo Vega Sanabria • Universidade Federal da Bahia - Brasil

ORCID: $\odot \odot \odot \odot-\odot \odot \odot 3-1991-5115$ guillermo.sanabria@ufba.br

Doutor em Antropologia pelo PPGAS do Museu Nacional/UFRJ, é professor no curso de Ciências Sociais e no PPGA da UFBA. Coordena a Comissão de Educação, Ciência e Tecnologia da ABA e faz parte da diretoria da Teaching Anthropology Network da EASA.

Este trabalho trata dos objetivos da formação em ciências sociais (no linguajar dos documentos oficiais, "o perfil profissional do cientista social") numa universidade fortemente voltada para as ciências agrárias. Nele retomo minha própria experiência como professor de antropologia num curso criado no final da década de 2000 na Zona da Mata Mineira. Embora o trabalho acadêmico tenha sido privilegiado como campo de atuação dos cientistas sociais, as atividades profissionais deles são hoje, aparentemente, mais diversificadas. Esse fato coloca sérios desafios ao ensino na graduação, sobretudo no que tange aos objetivos da formação nesse nível. Tais desafios parecem maiores após a relativa expansão do sistema universitário nas últimas duas décadas. Se, como é dito amiúde, a criação de novos cursos respondia à crescente demanda por profissionais qualificados na área, convém refletirmos: Como o ensino em nossos cursos se adéqua a tal exigência? Como responde à heterogeneidade e às expectativas de alunos e professores, especialmente após o aumento de pessoas oriundas de grupos historicamente excluídos da educação superior? Como esse cenário impacta nosso senso comum disciplinar acerca do que faz um cientista social?
This article examines the academic training in social sciences, or "the professional profile of the social scientist", provided at a Brazilian university firmly focused on the agricultural sciences. I debate my own experience as an anthropology teacher in an undergraduate program created in the late 2000s in Zona da Mata, Minas Gerais. Although academic jobs have always been a privileged career for social scientists, professional possibilities are currently more diverse. This fact poses serious challenges for undergraduate education, which became even more significant after the expansion of the Brazilian university system over the past two decades. If the creation of new courses responds to a growing and varied demand of professionals in the area, it is necessary to ask: how does the teaching of social sciences achieve this goal? How does it respond to the heterogeneity of students and teachers, especially after the recent increase in student admissions from historically excluded groups? How does this scenario impact the common sense about what a social scientist does?

Higher education. Social sciences. Diversity. University expansion. 


\section{Um antropólogo na Mata ou A formação universitária como campo do possível'}

If you know all the languages of the world

and you don't know your mother tongue or the language of your culture, that is enslavement.

But if you know your mother tongue or the language of your culture, and add all the other language of the world to it, that is empowerment ${ }^{2}$.

Ngugi wa Thiong'o

Este texto se baseia tanto na minha experiência pessoal quanto num projeto de pesquisa sobre ensino que desenvolvi nos cinco anos em que atuei como professor de antropologia no Departamento de Ciências Sociais (DCS) da Universidade Federal de Viçosa (UFV), na Zona da Mata de Minas Gerais. Além do intenso trabalho em sala de aula, desse período destaco meu empenho como coordenador da graduação em Ciências Sociais e do Mestrado Interinstitucional (MINTER) em Antropologia Social, realizado em parceria da UFV com o Programa de Pós-Graduação em Antropologia Social (PPGAS) da Universidade Federal do Rio de Janeiro (Museu Nacional). Essa parceria, aliás, num momento em que era notória em nível nacional a queda do financiamento estatal da educação superior, já fala das condições e dos recursos que ainda existiam na UFV, assim como das conexões possíveis no tipo de interior em que ela se encontra. Nesse sentido, observe-se logo que, ao falarmos de expansão e de interiorização da universidade, quase sempre o fazemos adotando, tacitamente, uma dupla perspectiva.

Por um lado, a perspectiva de quem se encontra nas metrópoles e entende que tudo o que não é capital ou litoral é interior. Se ela for levada à risca, Campinas - um centro metropolitano por si mesmo e sede de uma das principais universidades do país, seria tão interior quanto Cafelândia ou Fartura, no Estado de São Paulo. Evidentemente, desse modo são apagadas as diferenças existentes entre locais, espaços e regiões às quais nos referimos genericamente com dito termo. E, mais importante, oculta-se o fato de que o termo "interior" não apenas designa uma localização geográfica, mas, sobretudo, define um espaço simbólico e opera como uma categoria valorativa. Em particular, na hora de determinar os objetivos e as trajetórias educacionais em contextos tidos ora como metropolitanos ou cosmopolitas, ora como interioranos ou provincianos. Também quando se trata de assegurar as condições em que instituições e projetos educacionais se desenvolvem. Em outras palavras, o termo "interior" fala de hierarquias que, a rigor, independem de posições geográficas, mas que se relacionam ao acesso, distribuição e uso dos recursos disponíveis.

Por outro lado, ao falarmos de expansão da universidade, amiúde adota-se a perspectiva de quem tem como referência imediata o crescimento ocorrido nas últimas duas décadas, por meio do Programa de Expansão da Educação Superior
1 Pelas suas generosas contribuições a este trabalho, sou grato a dois pareceristas anônimos e às editoras do Anuário Antropológico e aos professores Douglas Mansur da Silva (Universidade Federal Fluminense) e Fabrício Roberto Costa Oliveira (Universidade do Estado de Minas Gerais-Barbacena), meus antigos colegas no Departamento de Ciências Sociais da Universidade Federal de Viçosa. Também agradeço aos professores Maria Elvira Diaz Benitez (Universidade Federal do Rio de Janeiro), Marcelo Moura Mello e Moisés Lino e Silva (Universidade Federal da Bahia).

2 "Se você conhece todas as línguas do mundo, mas não conhece a sua língua materna, ou a língua de sua cultura, isso é escravidão. Mas se você conhece a sua língua materna, ou a língua de sua cultura, e acrescenta a isso todas as outras línguas do mundo, isso é empoderamento" (tradução livre minha). 
Pública (Expandir), do Programa de Apoio a Planos de Reestruturação e Expansão das Universidades Federais (Reuni) e das políticas de ação afirmativa. Desconsidera-se, assim, uma compreensão histórica mais larga da implantação do sistema universitário brasileiro. Ela é fundamental para melhor entender não apenas as razões que têm pautado a criação de instituições de ensino, mas também suas características, mudanças e continuidades no presente (cfr. Saviani, 2010). Pense-se, por exemplo, como os modelos pedagógicos e organizacionais das universidades, assim como os objetivos e as diretrizes da formação neste nível, podem ser considerados à luz do processo de construção do Estado-nacional brasileiro. Com isso, lança-se luz, com efeito, sobre o surgimento do ensino das chamadas ciências agropecuárias, no início do século XX, em cuja esteira foram fundadas várias das atuais "universidades rurais" e outras instituições com esta marca - incluindo a UFV (Molina; Sanfelice, 2014). Ou, mais recentemente, sobre a política de "internacionalização" que dera origem, inclusive, à criação de universidades "no interior" com foco nas relações com outros países (ver o trabalho de De Lucca e Buti, neste dossiê).

A propósito de tal perspectiva histórica, na primeira parte deste texto apresento, grosso modo, alguns elementos que contemporaneamente podemos associar ao advento das ciências sociais numa universidade fortemente voltada para as ciências agrárias como a UFV. Essa foi uma questão instigante desde que cheguei a Viçosa, em abril de 2014, e deu origem a um projeto de pesquisa por meio do qual busquei objetivar minhas observações nesse sentido, ao longo dos seguintes cinco anos. O projeto tinha como referência a criação do curso de Ciências Sociais pelo Reuni e visava compreender as condições institucionais que o tornaram possível na UFV, mesmo com alguma resistência (cfr. Santos; Lopes; Fullin, 2015, p. 105-107; Gonçalves, 2016). Mais importante ainda, inclusive para mim enquanto antropólogo no início de carreira num lugar imprevisto, também era preciso indagar que tipo de antropologia era viável naquele contexto. Portanto, me interessava saber como as ciências sociais tinham estado presentes na história da UFV e o que implicava, agora, um certo pioneirismo dessa universidade no ensino e na pesquisa em áreas como a Sociologia Rural, a Extensão Rural e a Economia Doméstica ${ }^{3}$.

Nessa esteira, também busquei refletir sobre o propósito do ensino de ciências sociais no novo curso, nas condições da última expansão da universidade. A reflexão sobre o perfil profissional do cientista social da segunda parte do trabalho é um desdobramento dessa preocupação. A inserção no "mercado de trabalho", por sinal, fazia parte das dúvidas suscitadas internamente pela criação do curso, em 2007 (cfr. Santos; Lopes; Fullin, 2015; Gonçalves, 2016). Foi também uma das razões para que, uma vez criado, nele fosse privilegiada a formação na licenciatura, visando à formação de professores de sociologia para o Ensino Médio, em vez do bacharelado (cfr. Faria; Oliveira; Marques, 2018; Gonçalves, 2016). Os mesmos assuntos viriam à tona, mais uma vez, durante a reformulação do projeto político-pedagógico e da matriz curricular correspondente, quando fui coordenador da graduação (de 2016 a 2018). A reflexão sobre os objetivos da formação colocou-se também quando da implementação do MINTER (que coordenei de 2016 até o iní-
3 Trata-se do projeto "Dinâmicas institucionais, trajetórias intelectuais e configurações disciplinares: o ensino de Ciências Sociais na Universidade Federal de Viçosa", financiado parcialmente com três bolsas do Programa Institucional de Bolsas de Apoio a Projetos de Ensino da UFV. Nesse quadro também orientei o Trabalho de Conclusão de Curso intitulado Descobrindo a vocação das Ciências Sociais em Viçosa: Estudo sobre as publicações da Revista Ceres entre as décadas de 1940 e 1960 (cfr. Gonçalves, 2016 e Santos, 2015). 
cio de 2019) e, sobretudo, nos trabalhos que pretendiam a criação de um programa de pós-graduação em antropologia na Zona da Mata Mineira ${ }^{4}$.

Os objetivos da formação universitária são um problema bastante amplo e tema recorrente em nossas discussões. Contudo, minha intenção aqui é chamar a atenção, em particular, para algumas tensões e paradoxos históricos da educação superior no Brasil que, sugiro, ficaram mais evidentes após a última expansão das universidades. Por isso mesmo, proponho que as questões aqui apontadas estão longe de se restringirem a uma experiência "no interior", mas podem ser colocadas como desafio geral da formação universitária no país, inclusive no campo das ciências sociais em contextos "metropolitanos". Como mostrarei adiante, minha reflexão tampouco significa renegar a expansão (ainda inconclusa e imperiosa $)^{5}$, mas ecoa uma preocupação com as condições em que é possível garantir, retomando o velho mote, uma universidade pública, gratuita e de qualidade. Especialmente agora que ela se torna alvo preferencial de uma agenda oficial reacionária e as desigualdades educacionais de longa data são exacerbadas pela epidemia de Covid-19 que nos assola.

\section{Viçosa, 1922}

A UFV pode ser vista como resultado do voluntarismo político (a propósito, ver também o trabalho de Leal neste dossiê). Foi Arthur Bernardes, nascido em Viçosa e à época Presidente (sic) do Estado de Minas Gerais, o artífice da criação, em 1922, da Escola Superior de Agricultura e Veterinária (Esav). A Esav foi inaugurada em 1926, pelo próprio Arthur Bernardes, que então ocupava o cargo de Presidente da República. A improvável criação de uma instituição de educação superior num local "isolado e acanhado" como Viçosa na década de $1920^{6}$, respondeu, desde o início, aos interesses e ao projeto desenvolvimentista das oligarquias regionais (cfr. Santos, 2015, para referências). Implantada nos moldes dos land grant colleges dos Estados Unidos e sob direção de professores vindos desse país, o objetivo da Escola era introduzir o conhecimento especializado e as novas tecnologias da época para a modernização do campo. Em 1948, a Esav transformou-se em Universidade Rural do Estado de Minas Gerais (Uremg) e a marca estadunidense continuaria a se fazer visível nos anos seguintes. Além de professores locais serem treinados em cursos de pós-graduação nos Estados Unidos, um convênio com a Universidade de Purdue permitiu expandir a estrutura da Uremg e reforçou uma parceria que visava "colaborar para desenvolver no Brasil um reconhecimento público do papel da agricultura, da Economia Doméstica e da importância da agricultura eficiente e da vida rural satisfatória na economia" (Lima apud Arruda, 2003, p. 144).

Após nova reforma universitária no país, a Uremg se tornaria a Universidade Federal de Viçosa em julho de 1969. A UFV conta hoje com três campi: Viçosa, a 228 quilômetros de Belo Horizonte e 172 de Juiz de Fora; Florestal, criado em 1939 na região metropolitana da capital do Estado; e Rio Paranaíba, criado em 2006 na região do Alto Paranaíba/Triângulo Mineiro. Tem aproximadamente 20 mil estu-
4 Destaco, nesses trabalhos, as duas edições do evento $O$ ensino e a pesquisa de Antropologia na Zona da Mata mineira, em 2016 e 2017 . O evento reuniu, em Viçosa, antropólogos da Universidade Federal de Juiz de Fora - a outra universidade federal da região - e convidados dos PPGA do Museu Nacional, da Universidade de São Paulo, da Universidade de Brasília, da Universidade Estadual de Campinas, da Universidade Federal de Pernambuco, dentre outros. Também teve a participação de dois presidentes e uma ex-presidente da Associação Brasileira de Antropologia, assim como do coordenador da área na Coordenação de Aperfeiçoamento de Pessoal de Nível Superior.

5 Ver os dados sobre o alcance limitado da última expansão, apresentados por Vega Sanabria, Leal e Cariaga (2020) na Introdução deste dossiê.

6 A expressão é de José Maria Alves, professor aposentado da UFV, em matéria publicada num jornal local ao se referir à cidade neste período. Embora a criação da Esav tenha estimulado a urbanização de Viçosa no início do século XX, até 1960 o munícipio mal ultrapassava os 20 mil habitantes e mais da metade residia na zona rural. $\mathrm{A}$ população praticamente quadruplicou desde então, agora no encalço do crescimento da UFV, e o adensamento urbano intensificou-se com a verticalização e a explosão imobiliária (cfr. Maria; Faria; Stephan, 2014. Ver também Silva, 2012). Hoje em dia, conforme o Instituto Brasileiro de Geografia e Estatística (IBGE), a cidade tem uma população estimada de 78. 846 habitantes, além de uma população considerada "flutuante" de cerca de 20 mil pessoas - procedente de outras cidades mineiras e de outros 
dantes, cerca de 1.300 professores e 2.298 funcionários técnicos administrativos, conforme dados do censo institucional de 2017 (UFV, 2018). A universidade

já esteve, três vezes, entre as 100 melhores instituições de ensino superior do mundo na área das Ciências Agrárias e Florestais, de acordo com o QS World University Rankings, e entre as melhores de Minas Gerais, segundo o ranking da Times Higher Education e o Brics \& Emerging Economies?

Sem renunciar à hegemonia da agropecuária e apesar da resistência interna em nome da preservação dessa tradição (cfr. Gonçalves, 2016, p. 17-18), em 1978 a UFV começou a ampliar seu escopo institucional por meio de uma nova estrutura acadêmico-administrativa. Esse ano foram criados os quatro Centros de Ciências que existem até hoje em Viçosa: Ciências Agrárias, Ciências Biológicas e da Saúde, Ciências Exatas e Tecnológicas e Ciências Humanas, Letras e Artes - este último criado mais de 50 anos depois da inauguração da antiga Esav.

$\mathrm{Na}$ esteira das iniciativas do governo federal voltadas para a expansão da educação superior, a universidade registrou um novo crescimento a partir da década de 2000, inclusive nas Humanidades. A graduação em ciências sociais encetou suas atividades em 2009 como um curso noturno, com duas modalidades (licenciatura e bacharelado). A emergência de novas áreas de formação numa universidade onde, "por tradição, a área de Ciências Agrárias é a mais desenvolvida", parecia sinalizar um ponto de inflexão na própria concepção e dinâmica da UFV. Isto porque, como se reconhecia oficialmente, "apesar [sic] dessa ênfase na agropecuária, a Instituição vem assumindo caráter eclético [sic], expandindo-se noutras áreas do conhecimento, tais como Ciências Biológicas e da Saúde, Ciências Exatas e Tecnológicas e Ciências Humanas, Letras e Artes”. De acordo com essa visão, tratava-se de "uma postura coerente com o conceito da moderna universidade, tendo em vista que a interação das diversas áreas otimiza os resultados"».

O currículo da antiga Esav incluía, pelo menos desde 1939, a disciplina de Sociologia Rural, no intuito de compreender os modos de vida do campo, tidos como arcaicos e atrasados. Se o propósito era modernizar a agricultura pela difusão de tecnologias, também era preciso entender e transformar o comportamento dos camponeses locais que resistiam às mudanças. A sociologia rural era requerida, assim, enquanto saber aplicado, e a Esav seria a primeira instituição no país a ofertar esta disciplina como "curso complementar", no jargão da época. O responsável pela disciplina foi, durante muito tempo, Edgard de Vasconcelos Barros, um advogado com mestrado em Sociologia Rural pela Universidade de Wisconsin. Num artigo de 1945 - chamado "O ensino da Sociologia Rural, na ESAV" -, Vasconcelos elogiava a orientação dada à matéria e se orgulhava do "ato de quase indisciplina" da Esav ao ter se afastado dos padrões academicistas do ensino de sociologia então existentes no Brasil (ver Santos, 2015 para referências). A sociologia seguiria vinculada à chamada Extensão Rural, após criada a pós-graduação nesta área, em 1968. Nas décadas de 1970 e 1980, alguns professores tentariam introduzir uma perspectiva sociológica diferente da econometria e da difusão de
Estados, mormente vinculada à universidade. Dados sobre o número atual de habitantes disponíveis em: https://cidades. ibge.gov.br/brasil/ mg/vicosa/ panorama. Acesso em: $1^{\circ}$ set. 2020.

7 Ver seção "Apresentação", UFV. Disponível em: https:// www.ufv.br/apresentacao/. Acesso em: 15 maio 2020.

8 Texto vinculado ao link "História", UFV. Anteriormente disponível em http://www.ufv. br. Acesso em: 03 jun. 2015. 
tecnologias agrícolas, predominante nos cursos de Economia Rural e de Extensão Rural. Eles criaram um mestrado em Sociologia Rural, porém esta iniciativa encontrou resistências e só vingaria por poucos anos.

Em 1948, já convertida em Uremg, a universidade compreendia a Escola Superior de Agricultura, a Escola Superior de Veterinária, a Escola Superior de Ciências Domésticas, a Escola de Especialização (o que chamaríamos hoje de pós-graduação), o Serviço de Experimentação e Pesquisa e o Serviço de Extensão. Além da sociologia rural, nesta altura tinha se estabelecido outra área por meio da qual seriam introduzidos temas que, hoje, podemos entender como preocupações sociológicas da época: a Economia Doméstica. A Escola Superior de Ciências Domésticas, a primeira desse tipo no Brasil, abrigou o curso de Administração do Lar, em 1952, convertido em Curso Superior em Ciências Domésticas, em 1954. Eles originaram o Bacharelado em Economia Doméstica que, após mais de 60 anos, foi substituído pelo curso de Serviço Social, em 2016. Sem poder detalhar sua história, cumpre dizer que foi por essa via que alguns temas "antropológicos" emergiram, mesmo que em menor grau. Por exemplo, graças ao trabalho de mulheres que transitavam por essa área, iniciou-se em 1996 o Núcleo Interdisciplinar de Estudos de Gênero (NIEG), no qual tiveram papel fundamental, precisamente, as primeiras duas professoras com formação específica em antropologia na UFV 9 .

O que todas essas experiências, seja na extensão rural, seja na economia doméstica, tinham em comum era o fato de se ajustarem à ideia de umas ciências sociais aplicadas, concebidas como saberes auxiliares das ciências agrárias. Esse fato produziu um paradoxo notável. Por um lado, seu caráter auxiliar serviu por muito tempo para justificar a presença de alguns cientistas sociais - espalhados em vários departamentos como responsáveis de "disciplinas de massa" (sic), voltadas para os requerimentos de formação complementar de diferentes cursos. Por outro, relegou as ciências sociais a um papel secundário na estrutura universitária. Daí, aliás, a resistência que tanto a expansão da década de 1970 quanto a de 2000 encontraram nos setores que defendiam a tradição eminentemente agrária da universidade (Gonçalves, 2016, p. 17-18; Santos; Lopes; Fullin, 2015, p. 105). Parte considerável do meu próprio estranhamento na UFV relacionava-se à dificuldade que tive para lidar ao mesmo tempo com esta hierarquia disciplinar, tão firmemente arraigada inclusive entre alguns cientistas sociais que eram meus colegas no DCS, e as possibilidades de autonomia acadêmica que advinham da criação do departamento e da graduação em ciências sociais. O problema fundamental que este paradoxo revelava, sugiro, era o da legitimidade do conhecimento sociológico em si mesmo e seu reconhecimento num arranjo institucional que se pretendia mais diverso - a partir, pelo menos em parte, das dinâmicas geradas pela mais recente expansão ${ }^{10}$.

O trabalho de Leal, neste dossiê, é um relato vívido da experiência de ensinar "antropologia para filhos de agricultores" em São Raimundo Nonato, Piauí. Penso nele como um ponto de contraste em relação à minha experiência numa universidade detentora de uma tradição quase centenária, peça fundamental do agronegócio no Brasil e localizada na Zona da Mata Mineira - a mais pobre do Estado,
9 A primeira foi Alice Inês Oliveira e Silva, mestra em antropologia pela Universidade Estadual de Campinas (1985) e doutora em antropologia pela University College of London (1992). Alice Inês chegou à UFV em 1976 para trabalhar como assessora cultural na elaboração de um mapa do folclore regional e, depois, integraria - Departamento de Economia Rural. A segunda foi Maria de Fátima Lopes, professora desde 1981, bacharela em economia doméstica (1976), mestra em extensão rural pela UFV (1983) e doutora em antropologia pelo PPGAS do Museu Nacional (1995). Até 2008, quando passou a fazer parte do DCS, Fátima integrava o Departamento de Economia Doméstica. As duas encontram-se já aposentadas.

10 Conforme Gonçalves (2016, p. 21-22), até 2017, quando se discutia a criação do curso, havia na UFV 18 professores com alguma formação em ciências sociais. Eles estavam alocados nos departamentos de Economia Rural (07), Economia (05, que acabariam formando o núcleo original do novo curso), Economia Doméstica (03), Educação (02) e História (01). O maior número de professores 
depois do Vale do Jequitinhonha. Foi justamente o peso dessa tradição que me instigou a refletir sobre o tipo de ciências sociais que era possível em virtude dos contextos sociais e das culturas institucionais das novas e das antigas universidades no país. Porém, na origem dessa inquietação também se encontrava minha percepção de um ambiente acadêmico com tão forte apelo à identidade local (cfr. Silva, 2012) e tão diferente da tradição disciplinar e universitária em que eu tinha me formado no Brasil. A tradição disciplinar em que tinha me formado constituía, decerto, o mais firme esteio da compreensão que tinha do meu papel como antropólogo e da finalidade que atribuía ao ensino de ciências sociais nesse momento.

Tal compreensão, junto ao entusiasmo de me tornar professor numa universidade pública, talvez tenham feito com que demorasse a levar a sério a insistência com que algumas pessoas me perguntavam se pretendia ficar em Viçosa, se tinha me "adaptado à cidade". Depois de ter vivido em várias cidades brasileiras, de fato era a primeira vez que questionamentos como esses me eram colocados tão explicitamente - nunca me perguntaram antes, por exemplo, se tinha me adaptado ao Rio de Janeiro ou a Florianópolis. No caso do Rio de Janeiro, aliás, a pergunta mais frequente sempre foi por que tinha escolhido viver lá... Mais grave ainda, realmente pouco preocupado com o fato da UFV se localizar "no interior", minha posição inicial fez com que arriscasse enfrentar as reações que minhas atitudes e iniciativas na universidade suscitaram e que ignorasse, deliberadamente, minha dupla marginalidade (Evans-Pritchard, 1978, p. 303): pela origem disciplinar e pela condição de não nativo.

Conforme observa Silva (2012), em Viçosa se faz uma distinção entre "nativos" e "os de fora" ou "forasteiros". Os primeiros são, idealmente, os "nascidos, batizados e criados em Viçosa", e os segundos são, sobretudo, estudantes, funcionários e professores chegados em razão de seu vínculo com a UFV. Nas palavras deste autor:

O contraste entre a maior parte da população local e a maioria dos migrantes parece evidente, tanto em termos das diferenças de estilos de vida quanto de classe social, o que se traduz em assimetrias de poder, acesso desigual a bens culturais e a condições favoráveis à mobilidade social. Isto se dá porque é possível identificar no município um fenômeno singular: a migração de mão-de-obra altamente qualificada e de maior poder aquisitivo, para uma cidade considerada de pequeno a médio porte (Silva, 2012, p. 2).

Esta classificação é reproduzida dentro da UFV para distinguir professores "nativos" e "não nativos", amiúde sendo os primeiros membros da elite local formada pelas "famílias tradicionais". As "famílias da cidade" se distinguem pelos sobrenomes e os laços de parentesco e amizade, pelos vínculos de longa data com a instituição e por ocuparem postos de destaque na administração universitária, assim como nos grupos políticos que disputam permanentemente por ela.

Todavia, sem ter qualquer compromisso a priori com essa divisão, empenhei-me em diversos projetos que, com alguma ingenuidade, achei serem demons- na Economia Rural, aliás, deu pé ao pleito inicial para que o curso de Ciências Sociais integrasse o Centro de Ciências Agrárias e não o de Filosofia e Ciências Humanas (Gonçalves, 2016, p. 26). Meu ingresso, em 2014, na última vaga obtida pelo DCS por meio do Reuni, completou um quadro de 14 docentes efetivos (quatro antropólogos, quatro cientistas políticos e seis sociólogos). Até minha saída, no início de 2019, havia oito professores com formação em antropologia em toda a UFV: os quatro do DCS e mais quatro em outras unidades. Todavia, nem todos atuavam na área, nem estavam envolvidos nos projetos promovidos pelo DCS. 
trações inequívocas e suficientes de que tinha chegado para ficar. Nesse embalo, mas também diante das dificuldades que fui encontrando, sempre minimizei a pergunta se ficaria em Viçosa respondendo jocosamente que as universidades mais prestigiosas e ricas do mundo encontravam-se, "apenas por acaso", no "interior". Porque, diferente do que meus interlocutores supunham, essas dificuldades jamais estiveram relacionadas a qualquer "falta de adaptação" pessoal às limitações de morar no interior (o transporte intermunicipal ou interestadual, por exemplo), mas com a busca decidida de um espaço acadêmico. Contudo, nem as transformações objetivas produzidas pela expansão na universidade nos últimos anos, nem meu entusiasmo de outsider chegavam a ocultar o fato de que, em parte pela sua novidade, em parte pelo peso da tradição institucional, as humanidades e as ciências sociais se encontravam, se comparadas com as ciências agrárias, em condições de menor desenvolvimento e reconhecimento.

A ideia de dupla marginalidade é usada originalmente por Evans-Pritchard ao refletir sobre as implicações da experiência etnográfica. Este autor observa que, ao se afastar geográfica ou psicologicamente da sociedade de origem e se adentrar no conhecimento de uma outra, o antropólogo submete-se a uma experiência de radical estranhamento de seus valores, sem que, por mais radical que possa ser a imersão nesse outro universo, chegue a se converter num nativo. Assim, o antropólogo "vive simultaneamente em dois mundos mentais diferentes que se constroem segundo categorias e valores muitas vezes de difícil conciliação", tornando-se, ao menos temporariamente, "uma espécie de duplo marginal, alienado de dois mundos" (1978, p. 303). A reflexão que proponho a seguir teve origem na paulatina constatação das tensões produzidas, num nível institucional, pela presença, mesmo que marginal, das ciências sociais numa universidade de tradição agrária, os efeitos dessa condição marginal na formação na área, assim como os desafios produzidos pela relativa diversificação disciplinar e demográfica provocados pela expansão na UFV.

A reflexão ecoa, igualmente, num nível pessoal, minha dupla marginalidade, enquanto antropólogo e forasteiro, num curso de graduação que, fruto da expansão e localizado no interior, não deixa de representar uma tentativa de atualizar os ideais e os valores representados pelos objetivos gerais da nossa formação. Ao tomar como fio condutor as preocupações com a inserção profissional dos futuros cientistas sociais, meu intuito original era, sobretudo, objetivar os constrangimentos que então experimentara com relação às minhas próprias expectativas como professor de antropologia numa universidade pública. Também buscava, assim, reivindicar um lugar acadêmico diferente daquele que era atribuído às ciências sociais no ambiente em que vivi durante minha permanência na UFV. Contudo, como ficará evidente, a reflexão proposta tem um alcance bem maior. Isso sugere a necessidade de analisar com mais vagar eventuais especificidades institucionais e até mesmo uma distinção excessivamente rígida ou reificada entre "interior" e "metrópole". Não é porque tais especificidades inexistam ou porque tais distinções sejam desnecessárias, mas porque, como também fui compreendendo nos cinco anos que permaneci na UFV, junto aos aspectos idiossincráticos de minha expe- 
riência, era necessário considerar também alguns problemas de longa data na formação universitária no país. Boa parte desses problemas, insisto, não foram produto da expansão, mas escancarados por ela.

\section{Valores e ideais da formação (também, ou sobretudo, após a expansão) ${ }^{11}$}

Em novembro de 2019, a partir de um relatório divulgado pelo IBGE, foi amplamente noticiado no país: "negros são maioria pela primeira vez nas universidades públicas" do Brasil. Ao mesmo tempo, ainda com base no relatório, as notícias registravam que "pretos ou pardos estão mais escolarizados, mas desigualdade em relação aos brancos permanece". Como bem apontou o professor Luiz Augusto Campos sobre uma dessas publicações:

Embora tenhamos de fato alguns motivos a comemorar, a matéria induz a certos erros. Primeiro, porque o relatório do IBGE [...] não fala em universidades públicas, mas em ensino superior público, o que abrange atualmente as escolas técnicas estaduais e federais. Outras pesquisas indicam que pretos e pardos estão concentrados nelas e ainda sub-representados nas universidades, sobretudo as de maior prestígio. Segundo, a população autodeclarada preta e parda varia substantivamente no país, o que comumente faz com que o grande contingente de pardos no Norte e Nordeste termine contando para superar o déficit desses grupos no ensino superior do Sul e Sudeste ${ }^{12}$.

A desigualdade racial fica mais evidente ainda pelo fato de que, como também era noticiado, negros são maioria na universidade pública, mas concentram-se nos cursos menos concorridos e, de novo, acham-se sub-representados nos de maior prestígio como Direito, Medicina e Odontologia (cfr. também Carvalhaes; Ribeiro, 2019; Santos; Lima; Carvalhaes, 2020). Balbachevsky et al. (2019) observam, aliás, que o modelo da expansão fez com que grande parte do crescimento fosse absorvido pelo setor privado e por menos de meia dúzia de cursos muito tradicionais. Esse quadro é significativo justamente porque, após a relativa expansão do sistema universitário brasileiro nas últimas duas décadas, algumas contradições e desafios do processo começam a ser apontados por diversos autores (p. ex. Balbachevsky et al., 2019; Barbosa, 2020, no prelo; Carvalhaes; Ribeiro, 2019; CGEE, 2016; Mancebo, 2015; Neves, 2012; Schwartzman, 2013). Antes de serem consideradas críticas mal-intencionadas, tais reflexões merecem especial atenção porque alertam para constrangimentos que prejudicam os avanços que o relativo crescimento significou. Especialmente os avanços do ponto de vista político, no que tange às políticas de inclusão e de ação afirmativa ${ }^{13}$.

Clarissa Eckert Baeta Neves (2012), por exemplo, observa que apesar do que tinha sido, pelo menos até o início da década de 2010, o aumento do investimento público e privado no ensino superior, houve uma redução no ritmo de crescimento
11 Esta seção se baseia em textos preliminares apresentados nos seguintes eventos: mesa-redonda Novas universidades, novos campi, novas antropologias: docências, alteridades e expansão do Ensino Superior no Brasil, da 6 a. Reunião Equatorial de Antropologia, Universidade Federal da Bahia, dezembro de 2019; mesa-redonda Desigualdades e exclusões. Jovens, trabalho e as cidades, da IX Semana de Ciências Sociais, Universidade Federal Fluminense, Campos dos Goytacazes (RJ), maio de 2018; e Grupo de Trabalho 27: Ensinar e aprender antropologia, da 30a. Reunião Brasileira de Antropologia, Universidade Federal da Paraíba, João Pessoa, agosto de 2016. Agradeço aos organizadores e participantes desses eventos pelas valiosas contribuições.

12 Ver "Negros são maioria pela primeira vez nas universidades públicas", aponta IBGE, O Globo, 13 de nov. de 2019. Disponível em: https:// oglobo.globo.com/sociedade/ educacao/negros-sao-maioria-pela-primeira-vez-nas-universidades-publicas-aponta-ibge-24077731?utm_source=newsletter\&utm_medium=email\&utm_campaign=newstarde. Acesso em: 13 nov. 2019. Ver também "Pretos ou pardos estão mais escolarizados, mas desigualdade em relação aos brancos permanece", IBGE, 13 nov. 2019. Disponível em: https://agenciadenoticias.ibge. gov.br/agencia-sala-de-imprensa/2013-agencia-de-noticias/ releases/25989-pretos-ou-pardos-estao-mais-escolarizados-mas-desigualdade em-relacao-aos-brancos-permanece ?fbclid=IwAR2PzQ6j7FBR_Jca5PgL057U2rk0kmwyA 27pzOw8lcv5ES-19nwDsd15BSQ. Acesso em: 13 nov. 2019. 0 comentário do professor Campos, do Instituto de Estudos Sociais e Políticos da Universidade do Estado do Rio de Janeiro, foi publicado numa rede social na Internet em 13 de novembro de 2019. Agradeço a ele por me permitir reproduzi-lo aqui. 
da matrícula e têm persistido enormes desigualdades quanto à permanência dos alunos na universidade. Nesse sentido, a autora aponta que

(...) os grandes e recorrentes desafios são o da expansão da matrícula com democratização do acesso e da diferenciação da oferta de modo a garantir o atendimento das demandas da economia e da sociedade, a excelência da formação oferecida e uma equação adequada de financiamento da expansão" (p. 2, grifos meus).

Ao se referir ao crescimento da rede pública de ensino superior, Denise Mancebo (2015) também observa que

(...) esse processo de expansão fez-se acompanhar de uma reorganização do modelo de financiamento público. Para a rede pública, o aumento do financiamento significou novas exigências de eficiência e eficácia empresariais, expansão com contingenciamento de gastos, precarização das condições de trabalho, introdução de metas e prazos nem sempre compatíveis com um ensino de qualidade ou com o desenvolvimento de pesquisas verdadeiramente inovadoras (p. 15, grifos meus).

Dentre os desafios apontados por Neves e Mancebo, destaco os que se referem à qualidade da formação. A qualidade da formação é um princípio fundamental do marco legal da educação no país, contemplado expressamente na Constituição Federal de 1988 (inciso VII do Art. 206) e na Lei de Diretrizes e Bases da Educação de 1996 (inciso IX do Art. $3^{\circ}$ ). Ela se relaciona ao que os novos alunos universitários aprenderão ou deixarão de aprender e às suas posteriores possibilidades de inserção profissional. Falar em qualidade supõe, sobretudo, atentar para os conhecimentos e as habilidades mínimas necessárias que a formação visa garantir, tais como previstas, por exemplo, nas Diretrizes Curriculares Nacionais para os cursos de graduação em Ciências Sociais. Trata-se de um assunto sensível, em face do que o antropólogo George Zarur descrevia como a presença de "diplomados pouco mais do que alfabetizados" no mercado de trabalho brasileiro. Segundo Zarur, dados do Indicador de Alfabetismo Funcional, em levantamento feito pelo Instituto Paulo Montenegro e pela ONG Ação Educativa, revelam que "somente 62\% das pessoas com ensino superior e $35 \%$ das pessoas com ensino médio completo são classificadas como plenamente alfabetizadas, o que inclui não apenas habilidades linguísticas, mas também matemáticas" (apud Cavalcanti, 2013, n.p.).

A reflexão que proponho a seguir chama a atenção, por um lado, para os conhecimentos mínimos necessários que a formação nos cursos de Ciências Sociais visa garantir, especialmente tendo em vista o quadro universitário que se desenha no pós-expansão. Por outro, para as possibilidades de inserção profissional embutidas nos currículos e no conjunto da experiência formativa no ensino superior nesse contexto. Ao colocar em relação essas duas ideias, parto de um pressuposto fundamental: que as oportunidades de inserção profissional dependem tanto
13 A Lei $n^{\circ} 12.711 / 12$ reserva $50 \%$ das vagas de graduação das Instituições de Educação Superior (IES), em todos os cursos e turnos, para alunos de oriundos integralmente do Ensino Médio público e com renda familiar per capita inferior a 1,5 salários mínimos. Nesse percentual há uma destinação específica para pretos, pardos e indígenas, na mesma proporção desses grupos no Estado em que a IES se encontra. Conforme a V Pesquisa de Perfil Socioeconômico dos Estudantes das Universidades Federais, divulgada pela Associação Nacional dos Dirigentes das Instituições de Federais de Ensino Superior (Andifes, 2019), a maior parte dos estudantes de graduação das universidades federais no país provém de famílias com renda per capita de até 1,5 salários mínimos $(70 \%, 2)$, é parda ou preta (51,2\%), cursou o Ensino Médio em escola pública, e tem pais que não fizeram faculdade. Os cotistas, de qualquer modalidade, representam pouco menos da metade do total. Como também aponta a Andifes, a pesquisa confirma o que já era apontado por indicadores anteriores e mostra que é errada a afirmação de que as universidades federais são frequentadas majoritariamente pelos mais ricos. Fonte: Andifes. Disponível em: http://www. andifes.org.br/wp-content/ uploads/2019/05/V-Pesquisa-Nacional-de-Perfil-Socioeconômico-e-Cultural-dos-as-Graduandos-as-das-IFES-2018.pdf. Acesso em: 19 maio 2020. 
das dinâmicas do chamado mercado de trabalho quanto dos direcionamentos de nossa formação, ainda voltada, principalmente, para a carreira acadêmica. É claro que pouco adianta uma formação de qualidade se o mercado de trabalho arrefece, especialmente na medida em que ele continua a depender de concursos públicos. Basta ver o que acontece com centenas de recém-doutores que pareciam destinados a compor os quadros docentes das universidades e de outros setores do funcionalismo público, mas que, hoje em dia, no melhor dos casos, são obrigados a prolongar por tempo indeterminado esse estado ambíguo em que tendem a se converter os pós-doutorados no país. Porém, tampouco adianta termos um mercado de trabalho muito dinâmico, dentro ou fora da carreira acadêmica, se nossa formação não garante os conhecimentos e as habilidades necessárias para se inserir com êxito num ambiente de concorrência acirrada pelas vagas de emprego disponíveis.

Que conhecimentos e habilidades são essas, no caso da graduação em Ciências Sociais? Ou, conforme o linguajar das Diretrizes Curriculares Nacionais dos cursos da área, qual é nosso "perfil profissional"? E qual é, exatamente, o "mercado de trabalho" que mira nossa formação? O perfil proposto pelas Diretrizes indica que egressos dos cursos de Ciências Sociais atuarão como:

- Professores de Ensino Fundamental, de Ensino Médio e de Ensino Superior.

- Pesquisadores, seja na área acadêmica (fazendo pesquisa "básica”) ou não acadêmica (fazendo pesquisa "aplicada").

-Profissionais em atividades de planejamento, consultoria, formação e assessoria junto a empresas públicas, privadas, organizações não governamentais, governamentais, partidos políticos, movimentos sociais e atividades similares (Brasil, 2001, p. 26, grifos meus).

Repare-se que a divisão histórica entre bacharelado, que formaria pesquisadores e profissionais do terceiro setor, e licenciatura, que formaria professores para o ensino básico, pareceu bastar durante muito tempo para traçar o perfil profissional dos graduados. Porém, essa divisão se revela amiúde defasada e insuficiente na atualidade. Não apenas por causa das exigências de um mercado profissional supostamente mais diversificado e flexível, mas porque as pessoas que ingressam nos cursos têm suas próprias expectativas. Como aponta Elizabeth Balbachevsky, professora de Ciência Política da Universidade de São Paulo, “o novo estudante vem de uma família com menos recursos e tem uma expectativa mais pragmática em relação à graduação. Quer um diploma que lhe permita disputar espaço no mercado de trabalho"14.

A preocupação com isso que podemos seguir chamando de perfil profissional do cientista social em nossos cursos está longe de ser um problema banal, nem se reduz à maior ou menor empregabilidade dos egressos. É bem conhecida a angústia de muitos estudantes - também de professores - expressa nos reclamos
14 Isso explicaria, pelo menos em parte, um paradoxo do pós-expansão na nossa área: a queda da matrícula nos cursos de ciências sociais, pelo menos desde 2014. A citação da profa. Balbachevsky se encontra na matéria "Demanda por cursos de filosofia e ciências sociais despenca no país", publicada pelo Ranking Universitário da Folha de São Paulo, 07 out. 2019. Disponível em: https://ruf. folha.uol.com.br/2019/noticias/ demanda-por-cursos-de-filosofia-e-ciencias-sociais-despenca-no-pais.shtml. Acesso em: 20 out. 2019 (sobre este assunto ver também Santos; Lima; Carvalhaes, 2020, p. 44, no prelo). 
para que a formação universitária responda, em termos práticos e imediatos, às exigências do "mercado", mas também da "realidade", "dos problemas sociais", "do mundo lá fora”, etc. Essa angústia pode mesmo adquirir a forma de uma recusa da tradição teórica das ciências sociais e, no limite, de uma espécie de anti-intelectualismo mais ou menos blasé, mais ou menos beligerante. Daí que seja preciso ponderar com parcimônia a ideia de que o valor de nossa formação reside na sua aplicação prática imediata. Contudo, preocupações como essas também falam da distância que pode existir entre os requerimentos técnicos de um horizonte profissional, que se quer mais diversificado, e o cânone da formação, ainda ancorado nos moldes de uma tradição academicista e etnocêntrica.

Esse quadro é instigante porque aponta para dois problemas sociológicos fundamentais. Por um lado, os objetivos culturais de toda ação educativa, isto é, aquilo que almejamos com a educação dos novos membros da nossa comunidade de especialistas. Por outro, a produção de uma identidade profissional, o senso de pertencimento a um coletivo e o reconhecimento público do nosso trabalho como cientistas sociais. A rigor, não se trata de preocupações novas, mas muito antigas, das quais já se ocuparam os pioneiros das ciências sociais. Max Weber, por exemplo, num artigo de 1904, chamado "A 'objetividade' do conhecimento nas Ciências Sociais", tentava delimitar o campo de atuação e o que ele colocava como sendo os valores do cientista social. Algumas das preocupações colocadas no início do século XX por Weber e outros autores parecem ressurgir hoje quando falamos em perfis profissionais. Eis a seguir o que uma formação em ciências sociais oferece, ainda segundo as Diretrizes Curriculares Nacionais (Brasil, 2001, p. 26):

- Domínio da bibliografia teórica e metodológica básica;

- Autonomia intelectual.

- Capacidade analítica;

- Competência na articulação entre teoria, pesquisa e prática social;

- Compromisso social;

- Competência na utilização da informática.

Se o aluno pretende se formar na Licenciatura, espera-se que adquira, ademais, as seguintes habilidades específicas:

- Domínio dos conteúdos básicos que são objeto de ensino e aprendizagem no Ensino Fundamental e Médio;

- Domínio dos métodos e técnicas pedagógicos que permitem a transposição do conhecimento para os diferentes níveis de ensino (Id., ibid.). 
Por serem gerais, esses enunciados servem para exprimir certos ideais da nossa formação. O termo "ideal”, como sugere Jerome Bruner ao tratar da configuração dos currículos escolares, está longe de denotar aqui uma característica vaga ou distante. Ao contrário, ele expressa o fato concreto de que "culturas diferentes colocam diferentes ênfases no uso competente de diferentes modos e diferentes registros de pensamento” (1996, p. 26, tradução minha). Isto é, o que nós privilegiamos na nossa formação fala daquilo que consideramos fundamental para nos reconhecermos enquanto antropólogos, sociólogos e cientistas políticos, enfim, enquanto cientistas sociais. E é o que, afinal, nos diferenciaria de outros profissionais e especialistas de "o social". Desse modo, quando falamos da formação de nossos alunos, por exemplo, como futuros pesquisadores, é inevitável explicitar o que eles precisam aprender para serem reconhecidos enquanto tal. Em outras palavras, à luz dos valores (Weber) e dos ideais (Bruner) que orientam nossa formação, podemos refletir sobre as condições que a tornam possível, inclusive "no interior", no quadro dos novos campi e dos novos cursos criados no embalo da última expansão das universidades.

De que maneira um cientista social poderia participar em pesquisas sem ser treinado nas rotinas e no raciocínio do trabalho intelectual dos pesquisadores profissionais? Como fazer um levantamento bibliográfico sem conhecer a existência de acervos especializados e saber como utilizá-los? Como avançar nesse levantamento sem saber as diferenças entre um resumo, uma resenha e uma revisão bibliográfica? Como evitar o plágio sem aprender as técnicas de citação e de padronização de documentos como as da ABNT? Como acessar custosos acervos, coleções e portais de periódicos em diferentes línguas? Aliás, em tempos de "internacionalização" da universidade, como se inserir em espaços internacionais sem, de novo, o domínio de outras línguas, além do português? Ainda mais, quais são as chances efetivas de inserção profissional de um cientista social sem o domínio do português em sua variedade acadêmica? Outrossim: como pesquisar sem saber ler e interpretar tabelas, mapas, gráficos e dados estatísticos básicos como médias, modas e medianas? (para mencionar apenas medidas de tendência central e não de dispersão como variância e desvio padrão e, muito menos, a estatística de probabilidades).

A discussão não é se, com efeito, formamos ou deveríamos (ou não) formar pesquisadores na graduação. Parto do fato de que as Diretrizes Curriculares contemplam uma formação básica nesse sentido e nossos projetos político-pedagógicos de curso prometem que o faremos. Caso contrário, teríamos necessariamente que reconsiderar a oferta de disciplinas de metodologia e oficinas de pesquisa, a exigência de Trabalhos de Conclusão de Curso e, mesmo com o sucateamento atual, os esforços que dedicamos a projetos de Iniciação Científica, de Iniciação à Docência e estágios. $O$ melhor talvez seja perguntar-se o que significa um treinamento para a pesquisa neste nível. A partir de minha experiência na universidade, tanto como aprendiz na minha época de estudante quanto como professor, identifico algumas possibilidades na graduação em ciências sociais. Por exemplo: apreender os modos de leitura, de escrita, de fala e de escuta acadêmica; apropriar-se da 
paciência e da atenção que exige a prática da observação (participante ou não); conhecer, acessar e utilizar eficazmente acervos bibliográficos; saber construir e usar bases de dados; desenhar, aplicar e processar questionários; ler e interpretar tabelas, mapas, gráficos e dados estatísticos básicos como médias, modas e medianas (de novo, justamente, o nível mais qualitativo e descritivo da estatística)...

Por outra parte, de que modo seria possível promover que um aluno amplie seu horizonte cultural ao se familiarizar com outras línguas, precisamente em meio às denúncias de elitismo, colonialismo e outras queixas sobre a formação universitária? Há alguma forma de considerar o efeito de aceder a um conhecimento que, de outro modo, em nosso país fica restrito a uma minoria privilegiada econômica e educacionalmente? Não é igualmente problemático condenar um aluno universitário ao monolinguismo? Ou, mais grave, condená-lo ao analfabetismo funcional na nossa língua franca, o português (nem por isso menos colonial)? Mais amplamente, como inserir nossos alunos em diversos registros linguísticos e semióticos, como o da linguagem matemática e, em geral, o pensamento científico. Aliás, não segue sendo esta a tarefa principal da universidade?

O corolário de negligenciar esta discussão é um duplo fracasso: por um lado, o fracasso do professor, na tentativa de facilitar a apropriação por parte dos alunos dos modos de pensamento da ciência e da cultura universitária; por outro, o fracasso dos alunos, que continuarão a aumentar as taxas de evasão da universidade e a frustração de quem finalmente teve a oportunidade de chegar a ela, mas é imediatamente expulso ${ }^{15}$. Decerto a maioria dos professores universitários já experimentou o drama pessoal e os embaraços didáticos que o exercício de nosso trabalho nessas condições coloca. Todavia, também já experimentou a satisfação e o efeito politicamente libertador de ver um aluno pobre, negro e de uma escola da periferia sendo capaz de ler e interpretar uma tabela ou um gráfico sobre distribuição de renda no Brasil. De ver uma aluna ganhando uma nova consciência de si e se posicionando de um modo diferente no mundo ao se debruçar sobre estatísticas e séries históricas que revelam a diferença de salários entre homens e mulheres e entre brancos e negros, ou ao estudar as políticas de saúde sexual e reprodutiva num país como o nosso. Por isso, creio, podemos igualmente concordar na urgência de promover a autoestima e o empoderamento de nossos alunos mais pobres e subalternizados por meio do conhecimento da ciência, das humanidades, das artes e, na minha condição de antropólogo, da ciência que a antropologia é.

Nossos alunos mais pobres são o melhor testemunho do que significa, neste contexto, refletirmos sobre o fim último da educação superior. A formação universitária vai além do que um professor, modestamente, consegue fazer numa sala de aula e, porventura, inclui um leque mais amplo de experiências de ensino e de aprendizagem. Desse ponto de vista, pode calhar que alguns achem irrelevante ou presunçoso contemplar a possibilidade de que os alunos leiam em outras línguas e saibam interpretar uma série estatística. Todavia, essas habilidades continuam sendo necessárias no trabalho intelectual das universidades e em muitos ambientes profissionais alhures; nossas instituições, a rigor, continuam a ser avaliadas externamente por isso. Fazê-lo ou não fazê-lo tem efeito no prestígio institucional
15 Dados do Censo da Educação Superior, divulgados pelo Inep, "revelam um acréscimo desordenado na taxa de desistência do curso de ingresso, na avaliação da trajetória dos alunos entre 2010 e 2014 Em 2010, 11,4\% dos alunos abandonaram o curso para o qual foram admitidos. Em 2014, esse número chegou a 49\%". Fonte: Ministério da Educação. Disponível em: http://portal. mec.gov.br/component/tags/ tag/32044-censo-da-educacao-superior. Acesso em: 04 jun. 2019. Para uma discussão sobre qualidade da formação e evasão na universidade ver, por exemplo, Gilioli (2016), Lobo (2012), Santos; Silva (2011) e Villas Bôas (2003). 
(que conta na hora da contratação dos egressos, inclusive nas carreiras acadêmicas) e cada vez mais no financiamento público (vide a chamada "internacionalização" da universidade), para mencionar apenas dois aspectos dessa avaliação externa. E, mais importante ainda, tem efeito imediato na evasão (deveríamos dizer na expulsão) ou, se o aluno sobrevive na universidade, no tipo de trajetória e de inserção profissional possível para ele.

Nesse sentido, pelo menos dois gargalos da formação poderiam ser apontados, em relação ao novo quadro do sistema universitário no pós-expansão. Em primeiro lugar, a paulatina redução do trabalho docente à função de ensino. A respeito cito literalmente as Diretrizes Curriculares Nacionais para a Formação de Professores, produzidas pelo Conselho Nacional de Educação em 2015. Nelas se afirma que "ao segmentarem a educação superior pelo estímulo à expansão das matrículas e à diversificação institucional, na prática, as políticas para o setor, na maioria dos casos, contribuíram para a redução da educação superior à função de ensino” (Brasil, 2015, p. 6). Em alguns casos, o problema tem a ver, especificamente, com que o aumento considerável do número de alunos não foi acompanhado de um aumento proporcional do número de professores. Assim, os professores que atendem muitos dos novos cursos têm que se desdobrar para atender uma maior demanda interna e externa por disciplinas. Esse efeito deletério da expansão é grave, sobretudo nas universidades públicas, porque elas não se concebem, no Brasil, sem suas outras atribuições estatutárias, a saber: a pesquisa e a extensão. Ao concentrar o trabalho dos professores universitários no ensino, sem o tempo e os recursos imprescindíveis para a pesquisa e a projeção social que orienta a extensão, compromete-se seriamente a formação continuada do professor universitário, assim como a oportunidade de outras experiências formativas para os alunos.

Em segundo lugar, um paradoxo: a maior dedicação ao ensino tem acontecido, precisamente, sem a devida formação continuada e a reflexão pedagógica dos professores. É bem verdade que, pautadas por outros critérios de produtividade e prestígio, carreiras no magistério superior concedem menos valor ao aperfeiçoamento do ensino. Contudo, os professores universitários ficam, assim, numa situação precária para lidar com instituições e contingentes de estudantes cuja marca mais recente é a heterogeneidade. Tal heterogeneidade, no limite, chega a ser apontada como um defeito da expansão e das políticas de ação afirmativa sintetizado, ora em tom de denúncia, ora em tom condescendente, pela afirmação de que "o perfil da universidade mudou". Pretende-se assim chamar a atenção, como se fosse algo deveras inédito, para as dificuldades que muitos dos novos alunos têm para se inserir com êxito na cultura letrada da universidade. O que significa, a rigor, dizer que o perfil da universidade mudou? Que suas portas foram abertas para os alunos das escolas públicas, os pobres, os negros, os índios, os camponeses, os trabalhadores, as pessoas transgênero, os refugiados, as pessoas com deficiência?... Esquece-se de apontar, de toda forma, que também o perfil dos professores mudou e o despreparo secular da universidade enquanto instituição para lidar com tamanha diversidade (sobre novos professores universitários ver, 
neste dossiê, o comentário de Melo e Reis).

Ao refletirmos sobre os desafios pedagógicos e políticos provocados por essa diversidade, diga-se de passagem, convém não reduzi-la a sua dimensão socioeconômica, mas considerá-la num plano cultural abrangente. No que tange aos novos estudantes, em termos de diferenças geracionais mais prosaicas, pense-se nos embaraços colocados pelo uso de telefones celulares em sala de aula - seja como fator de distração, seja como ferramenta didática - e nas formas de leitura provocadas pela paulatina substituição dos textos impressos por dispositivos eletrônicos como esses. Igualmente, pense-se nos inevitáveis constrangimentos envolvidos no treinamento da atenção, da capacidade de escuta e do uso flexível da palavra numa discussão acadêmica; nos esforços que demanda a gestão do tempo, das rotinas de trabalho e dos recursos materiais e simbólicos que a universidade oferece (incluindo dentre esses recursos sua própria heterogeneidade social); ou, ainda, nas tensões que derivam da reflexividade, da reversibilidade do pensamento e do descentramento dos próprios valores que é inerente à paulatina apropriação do conhecimento científico e humanístico da universidade.

O que fazer então? Como professor universitário, minha resposta tem sido até agora: que a universidade se adéque pedagogicamente. Entre outras coisas, "pensar na formação pedagógica dos professores [...] de modo algum significa passar a exigir, ingenuamente, formação em licenciatura ou qualquer requerimento dessa ordem, mas promover de maneira sistemática a reflexão sobre as práticas de ensino e de aprendizagem na formação [...]” (Vega Sanabria; Duarte, 2019, p. 19). Adequar-se pedagogicamente tampouco significa diminuir o nível de exigência ou passar a oferecer uma educação de menor qualidade. Trata-se, antes de mais nada, de sermos politicamente coerentes com a legítima aspiração de "democratizar" a universidade (pública, gratuita e, de novo, de qualidade). A expansão da universidade continua a ser socialmente imperativa e moralmente inquestionável, mas expansão sem garantir as condições para uma formação de qualidade se torna politicamente inconsequente. Este apelo é mais urgente ainda na terrível crise sanitária e política que atinge frontalmente as universidades no momento. Neste contexto, mais uma vez, como garantir a qualidade no ensino para evitar o crescimento da desigualdade educacional no país? Como realizar os objetivos de aprendizagens previstos em documentos oficiais, nos projetos pedagógicos e nos currículos universitários? Como garantir que esses novos estudantes transitem com oportunidades reais de inserção nos programas de pós-graduação, nas autarquias federais, nas companhias privadas, nas organizações do terceiro setor, nos movimentos sociais, no retorno a suas comunidades de origem e nos locais que cada um almeja?

\section{A formação universitária como campo do possível}

Ao longo do meu trabalho como professor na UFV, procurei lançar mão da própria antropologia para, como disse no início, objetivar minha experiência nesse 
contexto. Isso incluía avaliar permanentemente o propósito, o alcance e a viabilidade da formação no curso de ciências sociais e, particularmente, do ensino de antropologia. Trocadilhos à parte, tratava-se, com efeito, de fazer do campus (da universidade) um autêntico campo (de pesquisa), empregando o conhecimento antropológico na análise do ensino e da aprendizagem na área (Vega Sanabria; Duarte, 2019, p. 20). Nessa tentativa, assim como a ideia de dupla marginalidade me permitiu entender a posição institucional que então ocupava, também refleti sobre meus múltiplos engajamentos acadêmicos desse período como uma situação liminar. O conceito de liminaridade, como lembra Gluesing (2016), se refere a uma condição ou a uma fase provisória, de transição entre um estado que não tem sido abandonado por completo e outro ainda não alcançado em definitiva.

O antropólogo Douglas Mansur da Silva, que foi meu colega no DCS, tinha apontado previamente a ideia de transição para analisar as tensões e conexões produzidas pelo caráter pesadamente local de uma universidade do/no interior e, ao mesmo tempo, sua inserção nas redes de excelência nacionais e internacionais, isto é, numa cultura acadêmica global (cfr. Silva, 2012). Essa análise sempre me pareceu relevante para pensar nas perspectivas do curso de ciências sociais, pelo menos na medida em que ainda fosse desejável uma formação sensível às demandas locais e que, simultaneamente, promovesse o acesso dos alunos e professores de hoje à cultura acadêmica da universidade, que se quer cosmopolita. Adicionalmente, a ideia de liminaridade fazia com que entendesse o trabalho que então realizava como cheio de potencialidades, no meio do caminho que por ventura existisse entre o status quo de umas ciências sociais tidas como auxiliares das ciências agrárias e a autonomia disciplinar que a criação do departamento e do curso de ciências sociais tinha aventado.

A liminaridade implica, com efeito, um estado de ambiguidade, haja vista que não se está num lugar nem em outro, mas também prenuncia uma nova maneira de ser e estar no mundo. Gluesing (2016) ainda lembra que Victor Turner descreveu a liminaridade como um "domínio de pura possibilidade" [realm of pure possibility], que pode dar origem a novas configurações de ideias no contexto de uma situação ritual. Pierre Bourdieu também tinha se referido à liminaridade como um "espaço do possível" [space of possible]. Meus engajamentos acadêmicos neste período exprimiam, justamente, o firme convencimento das possibilidades que meu trabalho oferecia, visando consolidar e expandir um projeto acadêmico em torno da antropologia e das ciências sociais a partir da UFV. Isso significava, decerto, superar o caráter secundário e instrumental atribuído a elas historicamente nessa instituição. Esse convencimento pautou meu trabalho em sala de aula, mas também na pesquisa sobre ensino e outros assuntos, na reforma curricular do curso de ciências sociais, na implantação do MINTER e na busca pela criação de um programa de pós-graduação em antropologia na Zona da Mata Mineira. Todos esses projetos criavam situações sequer imaginadas por mim ou por meus colegas pouco tempo antes e exigiam criatividade, enxergar novas perspectivas e se adaptar a novos cursos de ação. Porém, também exigiam reconhecer os limites das estruturas existentes e as resistências que enfrentaria uma nova dinâmica 
institucional, outra divisão social do trabalho acadêmico e formas alternativas da subjetividade organizacional (Gastón, 1999 apud Gluesing, 2016, p. 22).

Em 2014, já aprovado no processo seletivo pelo qual me tornei professor em Viçosa, surgiu a possibilidade de um novo concurso, agora na renomada faculdade de educação de outra universidade pública, numa capital do Sudeste brasileiro. Sabendo de minha trajetória e interesse nessa área, mas também que eu valorizava o vínculo institucional com um departamento de antropologia ou de ciências sociais, uma antiga professora, provocou-me com um ditado popular: "Você precisa decidir se quer ser rabo de baleia ou cabeça de sardinha”... No início de 2019, após cinco anos na Zona da Mata Mineira, fui redistribuído para o departamento de antropologia de outra universidade federal, agora numa capital do Nordeste (região que, para alguns, é mais uma forma de “interior”!). Contudo, as palavras dessa antiga professora, como sempre, foram inspiradoras o suficiente como para que, a partir de minha experiência em Viçosa, aprendesse que, sendo baleia ou sendo sardinha, o mais importante era aprender a se mover nas águas, ora mansas, ora turvas, da vida universitária. Essa aprendizagem também foi fundamental para que começasse a compreender meu trabalho como antropólogo e como professor, sobretudo, como um "domínio de pura possibilidade". Os lugares, as posições e as funções mudam, porém, tendo no horizonte os ideais e os valores da nossa (trans) formação como cientistas sociais, aprendi igualmente que o trabalho é feito, afinal, em cima do que é possível. 


\section{Referências}

ARRUDA, Maria Aparecida. Origem da Universidade Federal de Viçosa: Modernidade, agricultura de exportação e importação de modelos (1922- 1970). Cadernos de História da Educação, n. 2, p. 141-148, 2003.

BALBACHEVSKY, Elizabeth; SAMPAIO, Helena; ANDRADE, Cibele Yahn de. Expanding access to higher education and its (limited) consequences for social inclusion: the Brazilian experience. Social Inclusion, v. 7, n. 1, p. 7-17, 2019.

BARBOSA, Maria Ligia de Oliveira. A expansão desigual do ensino superior no Brasil. Curitiba: Appris, 2020.

BRASIL. Diretrizes Curriculares Nacionais para a Formação Inicial e Continuada dos Profissionais do Magistério da Educação Básica. Brasília: Conselho Nacional de Educação; Conselho de Educação Superior; Ministério da Educação, 2015.

BRASIL. Diretrizes Curriculares Nacionais para os Cursos de Graduação em Ciências Sociais. Brasília: Conselho Nacional de Educação; Conselho de Educação Superior; Ministério da Educação, 2001.

BRUNER, Jerome. The culture of education. Cambridge: Harvard University Press, 1996.

CARVALHAES, Flavio; RIBEIRO, Carlos Antônio Costa. Estratificação horizontal da educação superior no Brasil: desigualdades de classe, gênero e raça em um contexto de expansão educacional. Tempo Social, v. 31, n. 1, p. 195-233, 2019.

CAVALVANTI, Cintia. Qual o lugar da educação superior na formação para o mercado de trabalho brasileiro? São Paulo: Agencia Iberoamericana para la Difusión de la Ciencia y la Tecnología. 2013. Disponível em: http://www.dicyt.com/noticia/qual-o-lugar-da-educacao-superior-na-formacao-para-o-mercado-de-trabalho-brasileiro. Acesso em: 31 maio 2019.

CGEE - Centro de Gestão e Estudos Estratégicos. Mestres e doutores 2015: estudos da demografia da base técnico-científica brasileira. Brasília: Centro de Gestão e Estudos Estratégicos, 2016.

EVANS-PRITCHARD, Edward E. 1978. Os nuer. Uma descrição do modo de subsistência e das instituições políticas de um povo nilota. Perspectiva: São Paulo.

GILIOLI, Renato de S. P. Evasão em instituições federais de ensino superior no Brasil: expansão da rede, SISU e desafios. Brasília: Câmara dos Deputados, 2016.

GLUESING, Julia C. Liminality, anthropology, and the global organization. Journal of Business Anthropology, Special Issue 2, p. 13-34, 2016.

GONÇALVES, Erick F. Dinâmicas institucionais, trajetórias intelectuais e configurações disciplinares: o ensino de Ciências Sociais na Universidade Federal de Viçosa. Relatório final de Projeto de Iniciação Científica em Ensino. Viçosa: PIBEN/UFV, 2016.

IBGE - Instituto Brasileiro de Geografia e Estatística. Cidades/IBGE. 2020. Disponível em: https://cidades.ibge.gov.br/brasil/mg/vicosa/panorama. Acesso em: $1^{\circ}$ set. 2020.

LOBO, Maria Beatriz de C. M. Panorama da evasão no ensino superior brasileiro: aspectos gerais das causas e soluções. ABMES Cadernos, n. 25, p. 53-72, 2012.

MANCEBO, Denise. Educação superior no Brasil: expansão e tendências (1995- 2014). In: 37A. REUNIÃO NACIONAL DA ANPED, Florianópolis, SC. Disponível em: http://www. anped.org.br/sites/default/files/trabalho-gt11-3726.pdf. 2015. Acesso em: 31 maio 2020.

MARIA, Ana Cristina de Souza; FARIA, Teresa C. de Almeida Faria; STEPHAN, Ítalo I. 
Caixeiro. Um retrato da evolução urbana de Viçosa, MG: Impactos da federalização da UFV sobre a cidade (1969-2014). Revista Brasileira de Planejamento e Desenvolvimento, v. 3, n. 1, p. 37-54, 2014.

MOLINA, Rodrigo. S.; SANFELICE, José Luís. A gênese da institucionalização do ensino agrícola no Brasil. Educere et Educare, v. 9, n. 17, 213-229, 2014.

NEVES, Clarissa Eckert Baeta. Ensino Superior no Brasil: expansão, diversificação e inclusão. Comunicação no Congresso da LASA, São Francisco, CA. 2012. Disponível em: http://flacso.redelivre.org.br/files/2013/03/1114.pdf. Acesso em: 31 maio 2019.

SANTOS, André'G. Brandão dos. Descobrindo a vocação das Ciências Sociais em Viçosa: estudo sobre as publicações da Revista Ceres entre as décadas de 1940 e 1960. Trabalho de conclusão de curso (Bacharelado em Ciências Sociais) - Universidade Federal de Viçosa, Viçosa, 2015.

SANTOS, André'G. Brandão dos; LOPES, Leandro S.; FULLIN, Bruna. 2015. A origem, institucionalização e desafios das Ciências Sociais na Universidade Federal de Viçosa. Revista Café com Sociologia. DossiểHistória do Ensino de Sociologia, v. 4, n. 3, p. 96-109, 2015.

SANTOS, Clarissa Tagliari; LIMA, Raquel Guilherme de; CARVALHAES, Flávio. O perfil institucional do sistema de ensino superior brasileiro após décadas de expansão. In: BARBOSA, Maria Ligia de Oliveira (Org.). A expansão desigual do ensino superior no Brasil. Curitiba: Appris, 2020.

SANTOS, Georgina G.; SILVA, Lélia C. 2011. A evasão na educação superior: entre debate social e objeto de pesquisa. In: SAMPAIO, Sônia M. R. (Org.). Observatório da vida estudantil: primeiros estudos. Salvador: EDUFBA, 2011. p. 249-262.

SAVIANI, Demerval. A expansão do ensino superior no Brasil: mudanças e continuidades. Poíesis Pedagógica, v. 8, n. 2, p. 4-17, 2010.

SCHWARTZMAN, Simon. Higher education, the academic profession and economic development in Brazil. In: ALTBACH, P. G.; ANDROUSHCHAK, G.; KUZMINOV, Y; REISBERG, L. (Eds.). The Global Future of Higher Education and the Academic Profession - The BRICs and the United States. London: Palmgrave-Macmillan, 2013. p. 28-55.

SILVA, Douglas Mansur da. Cultura cosmopolita versus identidade local? Tensões, divergências e conexões entre moradores de uma cidade da Zona da Mata mineira. (Relatório final de pesquisa). Universidade Federal de Viçosa, Viçosa, 2012.

UFV - Universidade Federal de Viçosa. UFV em números (ano-base: 2017). Viçosa: Pró-Reitoria de Planejamento e Orçamento. 2018. Disponível em: http://www.ppo.ufv. br/wp-content/uploads/2018/11/UFV-EM-NÚMEROS-2018-Gráfica.pdf. Acesso em: $1^{\circ}$ set 2020.

VEGA SANABRIA, Guillermo; DUARTE, Luiz Fernando Dias. O ensino de Antropologia e a formação de antropólogos no Brasil hoje: de tema primordial a campo (possível) de pesquisa (antropológica). Revista Brasileira de Informação Bibliográfica em Ciências Sociais - BIB, n. 90, p. 1-32, 2019.

VILLAS BÔAS, Glaucia K. Currículo, iniciação científica e evasão de estudantes de ciências sociais. Tempo Social, v. 15, n. 1, p. 45-62, 2003.

WEBER, Max. A "objetividade" do conhecimento nas Ciências Sociais. In: COHN, Gabriel (Org.). Max Weber: sociologia. São Paulo: Ática, 1982 [1904]. p. 79-127. 